\title{
Music, neuroscience, and the psychology of well-being: a précis
}

\author{
Adam M. Croom ${ }^{1,2 *}$ \\ 1 Positive Psychology Center, University of Pennsylvania, Philadelphia, PA, USA \\ ${ }^{2}$ Department of Psychology, University of Pennsylvania, Philadelphia, PA, USA
}

\section{Edited by:}

Dan Lloyd, Trinity College, USA

Reviewed by:

Andrea Eugenio Cavanna,

Birmingham and Solihull Mental Health NHS Foundation Trust, UK

Douglas Bruce Johnson, Music

Conservatory of Westchester, USA

\section{${ }^{*}$ Correspondence:}

Adam M. Croom, Positive Psychology

Center and Department of

Psychology, Philadelphia, PA 19104,

USA.

e-mail:adam.m.croom@gmail.com
In Flourish, the positive psychologist Seligman (2011) identifies five commonly recognized factors that are characteristic of human flourishing or well-being: (1) "positive emotion," (2) "relationships," (3) "engagement," (4) "achievement," and (5) "meaning" (p. 24). Although there is no settled set of necessary and sufficient conditions neatly circumscribing the bounds of human flourishing (Seligman, 2011), we would mostly likely consider a person that possessed high levels of these five factors as paradigmatic or prototypical of human flourishing. Accordingly, if we wanted to go about the practical task of actually increasing our level of well-being, we ought to do so by focusing on practically increasing the levels of the five factors that are characteristic of well-being. If, for instance, an activity such as musical engagement can be shown to positively influence each or all of these five factors, this would be compelling evidence that an activity such as musical engagement can positively contribute to one's living a flourishing life. I am of the belief that psychological research can and should be used, not only to identify and diagnose maladaptive psychological states, but identify and promote adaptive psychological states as well. In this article I advance the hypothesis and provide supporting evidence for the claim that musical engagement can positively contribute to one's living a flourishing life. Since there has not yet been a substantive and up-to-date investigation of the possible role of music in contributing to one's living a flourishing life, the purpose of this article is to conduct this investigation, thereby bridging the gap and stimulating discussion between the psychology of music and the psychology of well-being.

Keywords: music, neuroscience, well-being, positive emotions, relationships, flow, achievement, meaning

\section{INTRODUCTION}

In Flourish, the positive psychologist Seligman (2011) identifies five commonly recognized factors that are characteristic of human flourishing or well-being: (1) "positive emotion," (2) "relationships," (3) "engagement," (4) "achievement," and (5) "meaning" (p. 24). Although there is no settled set of necessary and sufficient conditions neatly circumscribing the bounds of human flourishing (Seligman, 2011), we would mostly likely consider a person that possessed high levels of these five factors as paradigmatic or prototypical of human flourishing. Accordingly, if we wanted to go about the practical task of actually increasing our level of wellbeing, we ought to do so by focusing on practically increasing the levels of the five factors that are characteristic of well-being. If, for instance, an activity such as musical engagement can be shown to positively influence each or all of these five factors, this would be compelling evidence that an activity such as musical engagement can positively contribute to one's living a flourishing life. I am of the belief that psychological research can and should be used not only to identify and diagnose maladaptive psychological states, but also to identify and promote adaptive psychological states as well. In this article I advance the hypothesis and provide supporting evidence for the claim that musical engagement can positively contribute to one's living a flourishing life. Since there has not yet been a substantive and up-to-date investigation of the possible role of music in contributing to one's living a flourishing life, the purpose of this article is to conduct this original investigation, thereby bridging the gap and stimulating discussion between the psychology of music and the psychology of well-being.

First of all, what is music and what counts as musical activity? As easy as it is to recognize instances of music and musical activity when one encounters them in practical situations - for instance, when one perceives another person using an instrument to create a structured auditory stimulus that incorporates a combination of pitch, melody, and rhythm (Zatorre et al., 2007, p. 549), as when a friend plays a piece on the piano for you - there has in fact been much debate among scholars about how to precisely define these terms (for example, see the discussion in Cross, 2001). In fact, several scholars have argued against the appropriateness and very plausibility of there being precise and agreed upon definitions for concepts like music and art, articulated in terms of necessary and sufficient conditions, and have instead sought to understand these concepts in terms of relations that Wittgenstein called "family resemblances" (Wittgenstein, 1953; Sect. 67). In an influential article published in Cognitive Psychology, Rosch and Mervis (1975) characterized a "family resemblance relationship" as one in which, for every item subsumed under some category $X$, "each item has at 
least one, and probably several, elements in common with one or more other items, but no, or few, elements are common to all items" (p. 575; for an application of the family resemblance approach to concepts of natural language see Croom, 2011a; especially pp. 355-357). For instance, in an influential article published in The Journal of Aesthetics and Art Criticism, Weitz (1956) argued that the "attempt to discover the necessary and sufficient properties of art [or music] is logically misbegotten," and that the "contention that "art" [or "music"] is amenable to real or any kind of true definition is false" because art or music "has no set of necessary and sufficient properties" (p. 28; for discussion see also Kaufman, 2007; Tilghman, 2008; Irwin, 2011). So on this kind of view, there is no feature $x$ such that possession of $x$ is necessary and sufficient for some event $y$ to be categorized as a musical one. Instead, this view suggests that for each of the various events that we categorize as musical, we will more realistically find "a complicated network of similarities [among them that are] overlapping and criss-crossing: sometimes overall similarities, sometimes similarities of detail" (Wittgenstein, 1953, Sect. 66).

It is not my purpose in the present article to put a dog into this fight. This topic has been discussed elsewhere (Kaufman, 2007; Tilghman, 2008; Irwin, 2011) and a proper analysis and critique of these discussions should be reserved for its own occasion. Accordingly, for the purposes of the present article I will simply adopt an influential and intuitively appealing working definition of music that was proposed by the musicologist Ian Cross. As Cross suggests, "musics can be defined as those temporally patterned human activities, individual and social, that involve the production and perception of sound and have no evident and immediate efficacy or fixed consensual reference" (Cross, 2001, p. 33). As it will become clear throughout the course of this article, I will disagree about the inefficacy of music that is suggested by this definition, and so one might find it appealing to think of the features that we have so far identified in this section as features characteristic of music rather than features the possession of which are necessary and sufficient for the circumscription of music, an idea that is clearly compatible with the family resemblance conception (Wittgenstein, 1953; Rosch and Mervis, 1975; Kaufman, 2007; Tilghman, 2008; Croom, 2011a; Irwin, 2011). However, as a working definition, Cross's (2001) proposal is largely helpful and will be suitable for the purposes of the present discussion. (Importantly, one should also note that in this article certain kinds of musical activity will be associated with certain effects, and often these details will be evident in the context of discussion; however, more specific details about particular musical activities and their effects can always be found in the corresponding studies cited).

Now, it has long been speculated that musical activity might be good for the mind, body, or community at large (for instance, see Needham et al., 1962), but it has not been until recently that serious empirical work has been done on the behavioral, physiological, and psychological effects of human musical engagement. The recent increase in neuroscientific and psychological studies on human musical behavior are well motivated, for music is an intimate part of the human form of life and psyche. For instance, it has been well argued that music is a universal and crossculturally present feature shared by all humans (Darwin, 1871, p. 878 ) and is persistent throughout hominid evolutionary history
(Merriam, 1964; Blacking, 1995; Trevarthen, 1999; Cross, 2001; Levitin, 2006; Molnar-Szakacs and Overy, 2006; Brandt, 2008). Like linguistic competence, musical competence is unconsciously and automatically acquired upon exposure and develops along a standard biological timetable (Miller, 2000,p. 335), with a sensitive period (after which musical skill is substantially more difficult to acquire) occurring around 7 years of age (Habib and Besson, 2009, p. 279; see also Elbert et al., 1995; Schlaug et al., 1995; Watanabe et al., 2007). Structural features of music, such as pitch interval and pitch contour, are automatically encoded by all individuals (Trainor et al., 2002), which suggests that the functional architecture of the human brain has been adapted to process such musical stimuli (Peretz et al., 2001) and that human life has presumably found an intimate partner in musical activity for quite some time. In fact, musical instruments over 35,000 years old have been found (Conard et al., 2009), suggesting that the human preoccupation with music has been an enduring one, and that "music was an integral part of human life far earlier than first thought" (Miller, 2009, p. 19). Given the fact that human life finds an intimate partner in musical activity and has done so throughout our evolutionary history, one is naturally left wondering what musical activity might have to offer and how one might potentially benefit from it. Might musical activity do one some good, and possibly even facilitate a life of well-being? And if so, by what means can musical activity accomplish this?

In order to understand how music interacts with human sensitivities and influences human responses, it is helpful if we first discuss several features of our human constitution and evolution first. Now, thanks to our evolutionary history, we have been handed down many interesting and important biologically functional features (e.g., see Cosmides and Tooby, 1994; Cosmides and Tooby, 2000), only a few of which I will be able to discuss here for the purposes of this article. First, given the practical importance of being able to predict and anticipate future events (for instance, approaching food sources, predators, or mating prospects), it is not surprising that we find such future-oriented capacities among the functional capacities that our evolutionary history has handed down to us. Over 500 million years of naturally selective forces has favored the development of perceptual and cognitive systems with the capacity to predict and anticipate what is likely to occur, better enabling individuals to avoid dangers and capitalize on opportunities. Thus, it has been well argued by scholars that the biologically adaptive function of expectation is to prepare the organism for "appropriate action and perception" with regard to future objects and events (Huron, 2006, p. 3), which is an undeniably crucial capacity for successful survival and reproduction. Since the world is a dangerous place and it is safer for us to react to hundreds of false alarms than to neglect a single genuinely life-threatening event, nature has endowed us with perceptual and cognitive equipment that is sensitive to perceptual stimuli and susceptible to deviant or over-reaction, which musicians and "Composers can [exploit by] fashion[ing] passages [of patterned or structured auditory stimuli] that manage to provoke remarkably strong emotions using the most innocuous stimuli imaginable" (Huron, 2006, p. 6). In fact, it has been well argued that, "Since accurate predictions are of real benefit to an organism, it would be reasonable for psychological rewards and punishments to arise in response solely to the accuracy 
of the expectation" (Huron, 2006, p. 12, original italics). In other words, even though what we expect in music is typically of no practical harm to us, the fact that we expect in music still enables us to reap the experiential "rewards and punishments that arise in response solely to the accuracy of the expectation" we experience when we're actively listening to something as "innocuous" as music itself.

In addition to our capacity for anticipation and expectation, another functional feature that evolution has endowed us with is concerned with energy regulation. All biological organisms consume and require energy for the general maintenance of life, as energy is required for nervous, muscular, and metabolic functioning. Since one's energy must be generated from the food one consumes, and since the foraging for food and hunting of food is risky and time-consuming, organisms in general and humans in particular place a high premium on expending their energy efficiently. The importance of energy conservation is evidenced by the fact that brains and bodies drift toward low arousal states when action and thought are not required or when one's environment is static and unchallenging (Huron, 2006). Our body, including our brain, conserves energy by declining toward lower states of arousal when ecological conditions do not solicit our activity. Likewise, our bodies, including our brains, incline toward higher states of arousal when ecological conditions do solicit our activity (Huron, 2006). The purpose of the aforementioned biological features (of expectation and energy conservation) is to prepare our bodies, including our brains, to appropriately interact with upcoming events while at the same time attempting to do so as economically as possible in terms of energy expenditure (Huron, 2006). It is important to note that our level of arousal and attention does not simply incline and decline in accord with the occurrent demands of our ecological context or practical situation, but also with anticipated demands. And as one's various arousal states adjust in accord with one's changing expectations (which themselves adjust in accord with changing ecological conditions), the use of structured auditory stimuli to manipulate one's expectations could also thereby manipulate one's level of arousal and phenomenological experiences as well.

It is also important to note that different autonomic, physiological, and psychological responses are often solicited at different times and for different durations during emotional and anticipatory episodes. For instance, responses have often been characterizes as being of two types: (1) short-lived but immediate reaction responses, and (2) more contextually nuanced but slower appraisal responses (Huron, 2006). These two types of responses have been investigated by researchers and are typically distinguished in the following way. First, there are (1) reaction responses, which are usually composed of immediate reactions and learned schemas (Huron, 2006, p. 14), that are fast (e.g., usually reaction responses are solicited within $150 \mathrm{~ms}$ of stimulus presentation), non-conscious, and typically "defensive or protective in function" (Huron, 2006, p. 13). Affective arousal, for instance, has been shown to occur at an early stage of perceptual processing, often before one is even consciously aware of the perceptual stimulus (Zajonc, 1980; Bayens et al., 1990; Murphy and Zajonc, 1993; Esteves et al., 1994; Lang, 1995; Fox, 1996; Bargh, 1997). Interestingly, the presentation of a stimulus that is below the threshold level of one's conscious awareness can even influence one's affective ratings of other stimuli and can induce in one various novel physiological responses (Frijda, 1999).

Secondly, there are (2) appraisal responses, which are characterized as being slower than reaction responses (e.g., usually appraisal responses are solicited after $150 \mathrm{~ms}$ of stimulus presentation) and conscious, taking into consideration environmental, social, and other contextual factors (Huron, 2006). The more cognitive factors influencing emotional arousal range from prior conditioning operating over simple associations, confirmation or disconfirmation of what is familiar (Zajonc, 1980) or expected (Meyer et al., 1991), and various degrees of arousal afforded by memory. Cognitive factors influencing emotional arousal also involve the use of schemas, complex pattern comparisons, or other inferential processes (Landman, 1993; Gilovich and Medvec, 1995). Cognitive factors also play a major role in the elicitation of emotion because emotions are typically aroused by events that are appraised as relevant to one's tasks and concerns. In fact, it has been argued that determining which emotion is aroused by an event is largely dependent upon cognitive factors, since one's emotional reactions are largely dependent upon what one expects, personal assessments of causal agency and controllability, appraisals of task challenges and possible task-relevant actions, and so on (Lazarus, 1991; Frijda, 1999). Since goals and values differ among individuals, the relative emotional significance of an event will differ among individuals as well (Lutz, 1988; Markus and Kitayama, 1991; Mesquita et al., 1997; Frijda, 1999). Thus, emotional experiences include primary appraisals of an object as being of positive or negative affective valence - that is, as good or bad, pleasant or unpleasant (Lazarus, 1991) - as well as higher order cognitive appraisals of why the object was evaluated as it was (James, 1884, 1890, 1894; Lange, 1922). Reaction responses and appraisal responses are independent and need not (and often are not) consistent with one another (Huron, 2006), and the different combination of factors that mix into the cup of our emotional lives can make our emotional experiences quite variable and complex (Leventhal and Scherer, 1987), involving both lower and higher level processes. As Huron nicely puts it in Sweet Anticipation: Music and the Psychology of Expectation, different variations in our emotional responses evoke in us various feeling states, which "combine [in us] to create a distinctive limbic cocktail” (Huron, 2006, p. 18). Huron explains that "the emotions accompanying expectations are intended to reinforce accurate prediction, promote appropriate event-readiness, and increase the likelihood of future positive outcomes," and that "music making taps into these primordial functions [of emotion] to produce a wealth of compelling emotional experiences. In this way, musicians are able to create a number of pleasurable emotional experiences, including surprise, awe, "chills," comfort, and even laughter" (Huron, 2006, p. 4). Fiske (1996), summarizing an account of auditory expectation proposed by Meyer (1956, 1973), explains the relationship between auditory expectation and emotional arousal in the following way:

During the course of a musical work listeners create on-going expectations about what particular tonal-rhythmic events are likely to occur "next" in the piece. The expected next-event is based upon the culmination of events that have occurred 
in the piece so far. If this expected event is delayed or fails to occur at all, then emotional arousal will be stronger than it would be if the event had occurred as predicted [...] For a piece to be meaningful, the composer must tread a thin line between absolute predictability of musical events and the fulfillment of predictability versus absolute unpredictability through the frustration, inhibition, and avoidance of expected events. (p. 19, 107)

To mention just a few examples, Huron points out that, "tragedy can be evoked by using predominantly minor chords played within rich sonorities in the bass register. Suspense can be evoked using a diminished seventh chord with rapid tremolo. Surprise can be evoked by introducing a loud chromatic chord on a weak beat" (Huron, 2006, p. 2).

In order to account for how music and expectation interact to produce rich emotional experiences in music listeners universally, Narmour (1991) proposed that there are innate principles of auditory expectation that are universal and largely fixed in human psychology, presumably due to the fact that we have come preequipped with them as a result of our evolutionary constitution. Follow-up studies conducted by Schellenberg (1996) provided empirical support for Narmour's proposal, as well as confirming other data concerning the formation of expectations in music (Carlsen, 1981; Unyk and Carlsen, 1987). Some of the innate principles of auditory expectation that have been highlighted in the literature include, for instance, continuity of intervals, large tonal changes followed by a resolution toward an original tone, grouping by symmetry, similarity, and proximity, and others (see also Kubovy, 1999). These innate and universally present principles of auditory expectation form a bottom-up system that interacts with a top-down system of auditory expectation, which has instead been developed as a result of culturally acquired musical experience. For instance, top-down schemas include "practiced motor skills (such as brushing your teeth) or perceptual norms (such as watching traffic flows) [...] social norms (such as polite greeting rituals) or cultural norms (such as framing an object so that it is recognized as "art")," and insofar as a "schema is well entrenched in a mind, it becomes possible to provoke reaction responses by violating the schematic expectation" (Huron, 2006, p. 14). Different combinations of delay, violation, and satisfaction of one's auditory expectations cause arousal and tension in the listener, and the resolution of this tension can afford the listener pleasure (Rozin, 1999). By manipulating a listener's uncertainty of what will be heard and when they will hear it, musicians are able to produce different emotional responses in listeners, including positive emotional states (Huron, 2006).

For instance, if an upcoming stimulus accords with our expectation of it we typically experience an emotion of positive valence, whereas if an upcoming stimulus does not accord with our expectation of it we typically experience an emotion of negative valence (Mandler, 1975; Huron, 2006). This psychological principle is typically regarded as the primary affect (Olson et al., 1996). Even when an upcoming stimulus is negative, people tend to experience a positive emotional response when their expectation of the negative stimulus is satisfied; as Huron nicely puts the point, "It is as though brains know not to shoot the messenger: accurate expectations are to be valued (and rewarded) even when the news is not good" (Huron, 2006, p. 13). Again, this psychological principle seems to underwrite an appropriate biological function. Since what will happen to us in the near and far future is of the utmost importance to us, and since we generally respond better to events that we are physically and cognitively prepared for than to those that we are not, the capacity to anticipate changes in upcoming events provides us with the opportunity to reorient and prepare ourselves to appropriately engage with potential events and situations. It should also be noted, before moving on, that the pleasure we experience from apt violations of expectation, along with their resolution, is not a pleasure peculiar to music alone, but is found in other forms of pleasurable entertainment as well, such as comedy. For instance, several theories of pleasure in humor (see, e.g., Suls, 1972, 1977; Apter, 1982; Wyer and Collins, 1992) are similar to theories of pleasure in music (see, e.g., Kubovy, 1999, p. 146). Now that we have a preliminary understanding of how music can interact with human sensitivities and influence human responses, we will next turn our discussion to the question of how musical activity can positively influence each of the five factors that have been identified as characteristic of well-being. First, we will discuss recent findings from neuroscience that demonstrate how music can influence our emotions and lead us to positive emotional states.

\section{MUSIC AND POSITIVE EMOTION}

Recently, neuroscientists have been attempting to get clear on exactly which biological components are involved in musical pleasure and what role each of these components play. In a study published in Nature Neuroscience, Salimpoor et al. (2011) used a combination of techniques to investigate the biological mechanisms involved in musical pleasure. They were interested in investigating how "Music, an abstract stimulus, can arouse feelings of euphoria and craving, similar to tangible rewards that involve the striatal dopaminergic system" (Salimpoor et al., 2011, p. 257). In particular, they used functional magnetic resonance imaging (fMRI) and found that intense pleasure in response to music can lead to dopamine release in the striatal system. Further, they found that the anticipation of an abstract reward can result in dopamine release in an anatomical area distinct from the area implicated during experiences of peak emotional responses to music, namely, that the caudate was more involved during states of anticipation and the nucleus accumbens was more involved during the experience of peak emotional pleasure. So recent work in neuroscience has helpfully advanced our knowledge of which biological components are implicated during the pleasure we experience when listening to and anticipating music.

It has also been shown, in a study published in Brain by Sarkamo et al. (2008), that "music listening activates a wide-spread bilateral network of brain regions related to attention, semantic processing, memory, motor functions, and emotional processing," that "Music exposure also enhances emotional and cognitive functioning in healthy subjects and in various clinical patient groups," and that their "findings demonstrate for the first time that music listening during the early post-stroke stage can enhance cognitive recovery and prevent negative mood" (p. 866). In yet another article entitled, "Music enhances the effect of positive emotional 
states on salivary IgA," published in Stress Medicine, McCraty et al. (1996) demonstrated that "music affects autonomic function and [...] can be designed to enhance the beneficial effects of positive emotional states" (p. 173). They also proposed that, "music and emotional self-management may have significant health benefits in a variety of clinical situations in which there is immunosuppression and autonomic imbalance" (p. 167). An article published in Heart by Trappe (2010) also suggests that, "Music may not only improve quality of life but may also effect changes in heart rate and heart rate variability" (p. 1868). In that article Trappe (2010) further proposes that, "a proposed regimen of listening to music while resting in bed after open-heart surgery is important in clinical use" (p. 1868). In short, there is a growing body of work being published in neuroscience and medical journals arguing for the use of music to facilitate patient's recovery, health, and well-being, and my proposal is that music can be used to facilitate the well-being of normal individuals also.

The finding that musical engagement can lead to intensely pleasurable experiences in music listeners, and that these intensely pleasurable responses to music can lead to dopamine release in the striatal system (Salimpoor et al., 2011), is a useful finding, especially since it has been reported that individuals with high positive emotion experience less heart disease, are approximately $18 \%$ less likely to die of any cause (Seligman, 2011, p. 192), and develop fewer colds than people with average positive emotion and low positive emotion. Due to a difference in the presence of interleukin-6, a protein that causes inflammation, Seligman reports finding that, "The higher the positive emotion (PES), the lower the interleukin-6 (IL-6), and so the less the inflammation [... and that] Sheldon replicated this study with flu virus as well as cold virus, with the same results: positive emotional style is the driving factor" (Seligman, 2011, p. 200). Seligman further reports that, "More fibrinogen leads to more blood clots in the circulatory system [...] People with high positive emotions show less of a fibrinogen response to stress than those with low positive emotion" (Seligman, 2011, p. 207). So musical engagement might be implemented as a means of achieving positive physiological states such as these through its influence on our positive emotions.

In fact, music has been one of our oldest forms of stress reduction (Lehrer and Wookfolk, 1993, p. 9) and Avant et al. (1990-1991) report that musical engagement was shown to be more effective than, for example, progressive muscle relaxation and focused imagery in relieving stress. Music has been used to facilitate psychological well-being among the elderly (Laukka, 2007), and as one woman suffering with chronic illness reported, "I have this sensation of my body being a set of electrical circuits and the energy in the music passes right through my body and it feels like a cleansing or an undoing of kinks" (quoted from a woman going by the name "Celia," in Nicol, 2010, p. 356). Consistent with first person reports such as these, Krueger (2011) has rightly suggested that music is often a tool that can be used to "enact micro-practices" that can influence an individual's regulatory functions, such as their emotions (p. 2; see also Trevarthen, 1999; Juslin and Sloboda, 2001; Molnar-Szakacs and Overy, 2006, p. 239).

Moreover, there is now much empirical data collected showing that music can enhance the physiological states and emotional well-being of neonates while they are in the Neonatal Intensive Care Unit (DeNora, 2000, p. 81; Standley, 2001, p. 213; Krueger, 2011 , p. 9). Some of the positive benefits reported include facilitating various kind of "physiological and micro-behavioral stability" (Krueger, 2011, p. 9), including the stabilization and regularization of heart rate, blood pressure, and sleep cycles (DeNora, 2000, p. 81), while also reducing stress and calming infants, facilitating neurological and social development, and increasing the oxygen saturation levels of infants and reducing the time of their hospital stays (Standley, 2001, p. 213). In fact, the positive benefits of music can be extended to infants before they are even born. For instance, from as early as the 24th week of an unborn infant's life, their perceptual world is embedded within the sound of their mother's heartbeat (Hicks, 1992,p. 31). The child is not grown in an acoustic vacuum, but rather in an environment textured by the regularly occurring beats of the mother's heart and the melodic contours of her physiological states. These temporally regularized acoustic textures provide security to the infant as their regularity affords an environment in which the infant's expectations can be repeatedly satisfied and secured (Krueger, 2011, p. 13). It is unsurprising, then, that "one of the most stressful changes that occurs during the transition from intrauterine to extrauterine life is the loss of rhythm that the fetus has become accustomed to through months of being exposed to maternal movements, breathing, and heartbeat" (Collins and Kuck, 1991, p. 24). Research has suggested that an infant's transition from intrauterine to extrauterine life, and as a result, their transition from a more rhythmic to a more chaotic acoustic environment, "has the unwelcome effect of disrupting the infant's basic life processes [... and] adversely affects neonatal biorhythms which, in turn, affect sleep regulation and state lability" (Krueger, 2011, pp. 8-9; see also Kaminski and Hall, 1996, p. 46). In short, babies have good reason to be kicking and screaming as they enter the new world; for the new world is acoustically unstable, unpredictable, and in a constant state of unharmonious disequilibrium (Krueger, 2011, pp. 8-9).

The physiological, neurological, and emotional benefits of musical engagement are not restricted to neonates and infants, but extend to many others also (Koelsch, 2010). For instance, in a study published in Cerebral Cortex, Hutchinson et al. (2003) found that the brains of male musicians with piano experience showed significantly greater absolute and relative cerebellar volume compared to the brains of male non-musicians, and Gaser and Schlaug (2003) found in a study published in The Journal of Neuroscience that the brains of musicians showed a greater volume of auditory cortex compared to the brains of non-musicians. Schlaug et al. (1995) also found that the anterior half of the corpus callosum was significantly larger in musicians relative to non-musicians, and since the corpus callosum is the main fiber tract responsible for transmission of information between the left and right hemisphere of the brain, these findings suggest that inter-hemispheric integration and transfer of information is thereby enhanced in musicians relative to non-musicians. Bangert and Altenmuller (2003) also found that 20-min of music training was sufficient to elicit durable improvements in sensory-motor integration (see also Pascual-Leone et al., 1995), while Bangert et al. (2006) discovered that the benefits of such sensory-motor integration can even occur at an unconscious, precognitive level. 
A study conducted by Rosenkranz et al. (2007) utilizing transcranial motor stimulation (TMS) demonstrated that musicians have increased brain plasticity in motor areas relative to nonmusicians, and another study conducted by Bengtsson et al. (2005) utilizing diffusion tensor imaging (DTI) demonstrated greater white-matter coherence in the internal capsule of professional musicians. Bengtsson et al. (2005) showed that musicians that practiced the piano since childhood had a more structured pyramidal tract than non-musicians and that long-term musical practice implicates neural activity resulting in increased myelination of the fiber tracts involved during activity (although such plasticity in white matter was shown to become more limited as one matures with age). More recent studies using positron emission tomography (PET) and fMRI have also shown that white-matter bundles pertaining to the motor circuits in the brain are better structured in musicians than non-musicians (Habib and Besson, 2009, p. 280). Work by Chandrasekaran and Kraus (2010) suggests that musical training "induces neuroplastic changes throughout the nervous system" (p. 297) and work by Habib and Besson (2009) suggests that "beyond its effect on the plasticity of specific brain areas, music training, especially if started early in life, may enhance general plasticity of the brain and thus generalize to other learning domains" (p. 282). The enhanced cross-modal properties of the brains of musicians facilitates their audio-visual transfer of information, and several researchers have even used non-linguistic audio-visual games to successfully treat French dyslexic children (see Kujala et al., 2001; Magnan et al., 2004; Santos et al., 2007; Habib and Besson, 2009).

In another interesting study published in Science, data from magnetic source imaging (MSI) showed that musicians with extensive experience playing a stringed instrument had a larger cortical representation of the digits of the left hand compared with a control group of non-musicians (Elbert et al., 1995), which provides compelling evidence that practiced musical behavior can induce significant changes in the function and organization of the brain. Musical practice can even benefit patients with Parkinson's disease by helping them with "regulating gait and arm control" via priming and "entrainment of the motor system to the beat of the music," and stroke patients have been found to benefit from piano and drum training since these activities help to refine their motor skills, resulting in increased precision, speed, and smoothness of their movements (Koelsch, 2010, p. 132). Such findings are consistent with previous work demonstrating that musical training can facilitate greater concentrations of gray matter in motor cortices (Gaser and Schlaug, 2003).

Further, musical training has been shown to improve many aspects of auditory processing (Trainor et al., 2003; Peretz and Zatorre, 2005), including but not limited to improvements in pitch perception (Schneider et al., 2002), auditory stream segregation (Beauvios and Meddis, 1997), auditory attention (Strait et al., 2010), phonological skills (Forgeard et al., 2008), and the processing of prosody (Wong et al., 2007; Chandrasekaran et al., 2009; Bidelman et al., 2011) and emotions (Strait et al., 2009) in speech. Chandrasekaran and Kraus (2010) further point out that, "Musicians show less degraded brainstem representation of speech relative to non-musicians, as evidenced by faster neural timing, enhanced spectral representation, and better stimulusto-response correlations" and that "the differences in spectral representation between musicians and non-musicians are large, suggesting that musical experience protects against the debilitating effects of background noise" (p. 301; see also Parbery-Clark et al., 2009). Chandrasekaran and Kraus (2010) further demonstrated in their study that:

Musicians showed enhanced induced gamma-band activity (GBA), which is oscillatory activity in the $25 \mathrm{~Hz}-100 \mathrm{~Hz}$ range. Induced GBA is argued to reflect integration of topdown and bottom-up sensory processing [(Trainor et al., 2009)] [...] One year of music training in children has been shown to increase induced GBA relative to untrained participants [(Shahin et al., 2008)] [... and the evidence suggests that] GBA changes reflect increased efficiency of top-down processes, and that music has dramatic effects on cognitive-sensory interaction. (pp. 302-303)

Musical activity can also improve certain cognitive functions, as it has been shown to increase an individual's digit span (Fujioka et al., 2006) and working memory (Parbery-Clark et al., 2009). Although musical engagement implicates a vast range of brain areas, a detailed discussion of which would require an article in its own right (for instance, see the nice review by Zatorre et al., 2007), it is worth briefly mentioning that music has been shown to influence the amygdala, hippocampus, nucleus accumbens, anterior cingulate cortex, and insular cortex (Koelsch, 2010, pp. 133, 135). Music's influence on the amygdala, hippocampus, and the nucleus accumbens reflects the fact that music often influences the listener's emotional state (Koelsch, 2010, p. 133), and since music can influence the functioning of the hippocampus it has been argued that music training could cause "upregulation of neurogenesis in the hippocampus," helping both patients with depression and PTSD (Koelsch, 2010, p. 135).

It is plausible that the different forms of improved functioning resulting from musical experience that we have discussed above could either directly or indirectly influence our positive emotional states; directly, if positive affect is directly associated with improved functioning in the forms mentioned above, or indirectly if these forms of improved functioning lead one to greater practical success (e.g., through becoming talented, then rich, and famous), which may in turn solicit positive affect. Further, these findings are of practical import since studies have shown that individuals spend a significant amount of time and energy structuring their lives in ways that will facilitate positive feelings and emotions (Gollwitzer, 1993; Mischel et al., 1996), and so people may be able to implement knowledge from further music studies to facilitate positive feelings and emotions in their life. Indeed, many people seem to use music for this purpose intuitively, for as Frijda has pointed out, emotional regulation is often the major reason for "listening to music, or going out dancing” (Frijda, 1999, p. 205).

\section{MUSIC AND RELATIONSHIPS}

Musical engagement, however, can do more than simply influence one's emotional states. Musical engagement can also positively strengthen one's social bonds with others. In an article published in Heart and Lung, Nilsson (2009) demonstrated that actively 
listening to soothing music can increase a listener's level of oxytocin, a neuropeptide that plays a central role in the formation of social attachment and relationships in humans (Kosfeld et al., 2005) and other non-human species (Carter, 1998). Furthermore, music can influence our emotional states, which in turn influence our orientation toward the world, our comportment, and our action readiness, all of which are usually manifested in our observable behavior. Since our emotional states typically influence our observable behavior, and since others often take our observable behavior into consideration when interacting with us, our emotional states can also typically influence our interactions and relationships with other people. For example, the presence of positive emotions (such as happiness) tends to increase liking and social interaction with others, whereas the presence of negative emotions (such as sadness) tends to decrease liking and social interaction with others (Clark et al., 1996). So one way music can influence our relationships with other people is by influencing our emotions that in turn influence our relationships with other people. Emotional regulation is one of the important reasons for establishing relationships with others in the first place (Zillmann et al., 1986), and music is a useful medium for establishing those relationships. Through their influence on the emotions, music can facilitate the strengthening of bonds with others by demonstrating commitment in relationships and by providing evidence of those commitments to others (Frank, 1988). "Emotions have powerful effects in shaping and regulating social interactions, even outside the interactions that the emotions are about," Frijda claims, and "These social effects can be of large scope and magnitude" (Frijda, 1999, p. 205), being able to influence one's social functioning for time periods extending long after the event that originally initiated the emotional response (Frijda, 1999).

Indeed, many evolutionary psychologists have argued that social bonding and cooperation are fundamental features of human nature that facilitated our ancestor's survival and reproduction (Caporael and Brewer, 1991; Myers, 1999). For instance, many group selectionists argue that musical behavior is evolutionarily adaptive because it promotes group coordination and cohesion among members, synchronizing group actions, emotions, and identity (Merriam, 1964; Turnbull, 1966; Lomax, 1968; Hood, 1971; Seeger, 1987; Richman, 1987; Feld, 1994; Freeman, 1995; McNeill, 1995; Richman, 2000, p. 304; Brown, 2000a, p. 296; Brown, 2000b, pp. 231, 238; Trevarthen, 1999; Cross, 2001, p. 37; Christensen-Dalsgaard, 2004, Sect. 2.1; Levitin, 2006, p. 258; Brandt, 2008, pp. 6-7; see also Croom (2010b, 2012, under review) for a new account of the evolutionary origins of music that is based on principles of biological synchronization and efficiency, which is more explanatorily powerful than previous accounts but is still consistent with the particular points made here by group selectionists). For instance, synchronized chorusing has been found in certain species of insects (Otte, 1977; Greenfield and Shaw, 1983) and frogs (Wells, 1977; Klump and Gerhardt, 1992), and fireflies have been shown to synchronize their bioluminescent flashing at night (Buck, 1988). Researchers have also found that there are at least several hundred species of birds that perform precisely synchronized duets in order to stay in sync reproductively, strengthen partnership bonds, or defend territories (Brown, 2000b, p. 247). So it is plausible, many group selectionists argue, that musical behavior likewise evolved in humans to unite individuals into groups and strengthen partnership bonds (Brown, 2000b, p. 247). "[S]inging, marching, and laughing tunes the group," as Seligman (2011, pp. 144-145) says.

In his article "A neurobiological role of music in social bonding," Freeman (2000) proposed that the rhythmically repeated and predictable motions between agents that we find in music and dance facilitate joint action through the synchronization of attention and expectation between agents (p. 420). This, in turn, is hypothesized to facilitate interpersonal coordination, social bonding, and possibly even reproductive benefits. For instance, one hypothesis that has been suggested is that a group of male chimpanzees, upon discovering a resource such as large fruit trees, synchronize their chorusing in order to produce a stronger vocalization than other groups of males for the purpose of attracting the attention of - and thus increasing the probability of mating with - migrating females (Merker, 2000, pp. 318-320; see also Wrangham, 1975; Wrangham, 1979). In this sort of way, synchronized group chorusing among chimpanzees and even humans might have conferred reproductive advantages, in addition to more obvious advantages in hunting and combat. Further, in order to explain the fact that the cranial capacity of our hominid ancestors' skulls doubled in size from approximately $600 \mathrm{~cm}^{3} 5000,000$ years ago to approximately $1,200 \mathrm{~cm}^{3}$ in the present, Humphrey (1986) has argued that those with larger, more robust brains had more computational power with which to solve social problems and dilemmas, which in turn positively contributed to their sociality and interpersonal relationships (see also Seligman, 2011).

In any case, regardless of the specific details of our evolutionary past, a great deal of our behavior today is in fact oriented toward strengthening our social bonds with others, and we typically experience better physical, mental, and emotional health when we have others to bond with (Argyle, 1999; Myers, 1999). Our positive emotions are largely influenced by and directed at others (Seligman, 2011) and it has been shown by several scholars that participating in enjoyable activities with friends is predictive of subjective well-being (Heady et al., 1985). Argyle, for instance, mentions that "social clubs, music, and voluntary work all show strong positive effects" for the well-being of the individuals participating in these activities (Argyle, 1999, p. 353). Given the fact that musical performances are often done with or for others, a commitment to a musically engaged life could positively contribute to one's wellbeing. Commitments such as career involvement, marriage, and religion have been associated with improved overall life satisfaction (Batson and Ventis, 1982; Kessler and Essex, 1982; Cantor and Sanderson, 1999), and since a musically structured life is one constituted by genuinely engaged involvements and commitments to musical investments, rehearsals, and performances, we have good reason to believe that musical activity can also positively contribute to one's overall life satisfaction. As Argyle writes:

A lot of leisure activities [for example, musical activities] are done in groups, such as [... music bands, ] choirs, and teams, and this is a source of happiness [...] the moodinducing nature of the[se] activities, such as dancing and music, and also the social support and social integration [involved in these activities, all positively contribute to one's 
level of wellbeing]. Indeed, it is possible to fulfill a variety of social needs through such activities - [for instance, one's needs] for intimacy, public performance, cooperation, and so on. (Argyle, 1999, p. 364; see also Argyle, 1996)

Other work has shown that individuals in close relationships with others cope better with stress and illness (Cohen, 1988; House et al., 1988; Nelson, 1988) and are less likely to die prematurely (Abbey and Andrews, 1985; Perlman and Rook, 1987) than individuals lacking in close relationships. Individuals that have a network of social support are likely to live longer than individuals that do not (Vaillant, 2003), and when participants were asked which element in life would bring them the most happiness, most cited love, or close interpersonal relationships (Freedman, 1978; Berscheid, 1983; Pettijohn and Pettijohn, 1996). It should be clear that participating in a band or musical group can serve as a means for building close relationships with others, since the mastery of a musical work provides the band members with a common purpose, common ground, and a potentially extensive amount of time together for the sake of rehearsal and performance. That is to say, participation and commitment to activities, such as musical events, often involves participation with and commitment to others, as many activities involve a social component and are of sociocultural significance (Erikson, 1950; Havighurst, 1972).

Furthermore, Brickman and Coates (1987) have shown that individuals often benefit more from helping and caring for others than they do from being helped and cared for themselves, and so, as Cantor and Sanderson (1999) point out, social contact and participation with others "may be associated with well-being not only directly by providing social support and assistance, but also indirectly by providing individuals with opportunities to care for others" (p. 235). In fact, Seligman (2011) reports that doing kind deeds for others produces the most reliable momentary increase in well-being than any exercise his team has tested and that "Other people are the best antidote to the downs of life and the single most reliable up" (p. 20). Musicians, like other performers, have the opportunity to care for others every time they perform. Insofar as music listeners enjoy listening to music, musicians have the opportunity to provide listeners with something that they enjoy, and thereby have the opportunity to perform a kind deed for others every time they perform. And insofar as performing kind deeds for others can reliably produce momentary increases in well-being, as Seligman (2011) has argued, this suggests that performing music for others can produce momentary increases in well-being also. Furthermore, insofar as a musician is cognizant of the fact that their performance is providing pleasure and momentary increases of well-being to their listeners, that musician is afforded evidential support for believing that they have actually accomplished something (see Music and Accomplishment) and that their actions are meaningful or purposeful (see Music and Meaning; see also Seligman, 2011). Thus, participation and commitment to shared activities can facilitate social bonding or connection with others (Baumeister and Leary, 1995), often times through the development of shared sensitivities and norms for evaluative ascriptions (Croom, 2010a,b, 2011a,b, 2012), which influence both the individual and the larger community within which that individual participant is engaged (Putnam, 1995).

\section{MUSIC AND ENGAGEMENT}

Musical activity is not only of practical application for the cultivation of positive emotions and strong interpersonal relationships, although musical activity often does serve these functions. Music can also positively influence other features that we have identified as characteristic of a flourishing life. Another important feature that we identified as characteristic of a flourishing life was the presence of flow experiences, i.e., experiences where "psychic energy flows effortlessly" (Csikszentmihalyi, 1990, p. 36) and one is attentively absorbed and skillfully engaged in an activity that one finds valuable. As Seligman describes it, "engagement, is about flow: being one with the music, time stopping, and the loss of selfconsciousness during an absorbing activity" (Seligman, 2011, p. 11). Features of flow experiences include perceptions of control, task focus, and a resultant absence of public self-consciousness (Vallerand et al., 2003; Mageau et al., 2005; Forest et al., 2008; Philippe et al., 2009). Previous research has shown that, in contrast with people that do not experience flow, people with flow experiences typically report higher levels of well-being (Haworth and Hill, 1992; Haworth and Evans, 1995; Haworth, 1997; Csikszentmihalyi, 1999; Eisenberger et al., 2005; Carpentier et al., 2011), positive emotions, positive moods, and pride (Han, 1988; Clarke and Haworth, 1994; Bloch, 2002; Delle Fave and Massimini, 2004).

The experience of flow is no stranger to musicians, and in fact, Tchaikovsky had famously said that, "Do not believe those who try to persuade you that composition is only a cold exercise of the intellect. The only music capable of moving and touching us is that which flows from the depths of a composer's soul when he is stirred by inspiration" (quoted in Vernon, 1970, p. 58). Of this fluid, flowing state of the mind and body, Tchaikovsky further remarked that it was "a great thing if the main ideas and general outline of a [musical] work come without any racking of brains, as the result of that supernatural and inexplicable force we call inspiration" (p. 58). Wolfgang Mozart also reported that, "When I am, as it were, completely myself, entirely alone, and of good cheer [...] my ideas flow best and most abundantly. Whence and how they come, I know not; nor can I force them" (quoted in Vernon, 1970, p. 55).

One psychologist that has done extensive research in this area is Csikszentmihalyi, and in his (1990) book Flow: The Psychology of Optimal Experience, he reports finding that people are happiest when they are most absorbed in their actions and experiencing flow. In their article "Effects of asynchronous music on flow states and shooting performance among netball players," Pates et al. (2003) show that musical engagement can indeed "enhance performance [on concentration tasks] and trigger emotions and cognitions associated with flow" (p. 426). Work carried out by Chandrasekaran and Kraus (2010) also suggests that, "Musicians show less degraded brainstem representation of speech relative to non-musicians, as evidenced by faster neural timing, enhanced spectral representation, and better stimulus-to-response correlations" and that "the differences in spectral representation between musicians and non-musicians are large, suggesting that musical experience protects against the debilitating effects of background noise" (p. 301; see also Parbery-Clark et al., 2009). Findings like this are relevant for our understanding of flow because, insofar 
as background factors that distract someone from engaging attentively with their current activity interrupts their experience of flow (Nakamura and Csikszentmihalyi, 2002; Carpentier et al., 2011), and insofar as the reduction of background noise that musical experience affords can help facilitate one's engaging attentively with their current activity, it is arguably the case that musical experience can thereby positively contribute to one's becoming fully absorbed in their actions and achieving the experience of flow.

Kubovy (1999) has previously linked Csikszentmihalyi's (1975) work on flow to the experience of virtuosity, and he explains that in flow experiences we often experience the exercise of virtuosity, whereby "an act is performed with virtuosity if it is difficult for most people to do but is carried out with ease and economy" by oneself, and often accompanied by "the pleasure we have when we feel we are doing something well" (Kubovy, 1999, pp. 147-148). We can even experience the pleasures of virtuosity relative to our prior lack of ability, as, for instance, Sudnow $(1978,1979)$ describes his experience of accomplishment over the 6 year period in which he learned to improvise jazz on the piano. "The pleasures of virtuosity make us want to do things well," Kubovy (1999) remarks, "and hence we play in order to achieve this pleasure, which gives us skills we need to survive" (p. 148). In flow experience we are optimally attentive and tuned in to what we are doing, deploying our most developed skills which in turn afford us feedback in the form of positive emotions, a sense of accomplishment and purpose, and even better relationships (Seligman, 2011, p. 24). So musical practice and performance, as a conduit for flow experiences, likewise offers us an avenue for attunement, perceptual and cognitive exercise, the accomplishment of successful motor execution, the experience of positive emotional states and pleasurable auditory stimulation, the meaning derived from participating in a larger social entity and offering a distinctive contribution, and connecting with others.

\section{MUSIC AND ACCOMPLISHMENT}

Up to this point we have now discussed how musical engagement can positively influence one's positive emotions, relationships with others, and flow experiences. Next, we will discuss how music can positively influence one's sense of accomplishment and meaning in life. First, it seems clear that music can in fact contribute to one's sense of accomplishment. For instance, Tchaikovsky once said of his musical career that, "I can affirm with joy that I make continual progress on the way of self-development, and am passionately desirous of attaining the highest degree of perfection of which my talents are capable" (quoted in Vernon, 1970, p. 60). Many practicing musicians are likely to feel the same way, and accordingly, musical involvement can help people attain a sense of personal accomplishment. Numerous findings have demonstrated that those individuals that made the most significant accomplishments in their field of practice were those that spent the most time devoted to carefully practicing what it is that they do (Chase and Simon, 1973a,b; Hayes, 1981; Bloom, 1985; Ericsson et al., 1993; Weisberg, 1999). For instance, Bloom (1985) conducted a study based on interviews of accomplished professionals from a broad range of fields - including, for instance, highly accomplished scientists (e.g., mathematicians and neurologists recognized for excellence in early career development), musicians (e.g., award-winning pianists), artists (e.g., award-winning sculptors), and athletes (e.g., Olympic swimmers and tennis players recognized among the world's top 10) - and found that accomplishment by individuals in each of these fields required years of dedicated and attentive practice to their particular activity, while also partly depending on the support provided by one's friends and family, and the informed guidance provided by one's parents, coaches, and role models (Bloom, 1985; Weisberg, 2006). A study conducted by Ericsson et al. (1993) that focused on the accomplishment of musicians in particular found that accomplished professional musicians spent, not only more time practicing than less accomplished musicians, but also more time sleeping, suggesting that sleep can facilitate learning from attentive and effortful musical practice (Ericsson et al., 1993; Weisberg, 2006). But the main finding for our purposes here is that what distinguishes a truly outstanding musician, or any other specialist or professional, from those of less or no skill is the amount of structured motor behavior they have unreflectively available for action, which is itself typically the result of undergoing hard-earned practice and repetitive motor drill (Seligman, 2011). For instance, studies have found that world-class musicians averaged $10,000 \mathrm{~h}$ of solo practice by the time they were 20 years old, in contrast to $5,000 \mathrm{~h}$ for the next lower level musician, and in contrast with $2,000 \mathrm{~h}$ for merely serious amateur musicians (Ericsson et al., 1993; Weisberg, 2006).

Similar findings have been demonstrated outside of the domain of musical performance - for instance, in musical composition, poetry, and chess (Chase and Simon, 1973a; Hayes, 1981; Weisberg, 1999) - and this consistent finding is now frequently referred to as the 10-year rule (Hayes, 1981, 1989; Gardner, 1993; Weisberg, 2006) for the straightforward reason that "if you want to become world class at anything, you must spend $60 \mathrm{~h}$ a week on it for 10 years" (Seligman, 2011, p. 115). Thus, Aristotle's insight on the nature of excellence seems to have been on the right track. As Aristotle advised, "virtues are formed in man by his doing the actions [...] the Good of Man comes to be "a working of the Soul in the way of Excellence" [...] for as it is not one swallow or one fine day that makes a spring, so it is not one day or a short time that makes a man blessed and happy" (Aristotle, 1911; Book II, 4; Book I, 7). "Human excellence," in musicality as in morality, comes about as a result of habit (Aristotle, 1911; Book II, 1).

I previously mentioned in Section "Music and Relationships" that one can use participation in a band or musical group as a means for building close relationships with others, since the mastery of a musical work provides the band members with a common purpose, common ground, and a potentially extensive amount of time together for the sake of rehearsal and performance. But not only are individual members brought together to collectively constitute the larger whole that is their band, but this collective constitution also typically assigns each member a unique role to perform within that larger whole. Since each member is assigned a role to perform, and since each member can perform that role poorly or proficiently, the musician's ability to come through and deliver during their musical opportunities can provide them with the sense of accomplishing their musical part successfully, instead of with ineptitude. A well executed and emotionally inspiring 
musical performance requires not only musical knowledge and technique, but also a performer's confidence and social grace, and the collective manifestation of these features in a single musical act by the performer surely counts as a bona fide accomplishment (indeed, audiences often pay good money to witness such accomplishments). Also, since people often listen to music because they enjoy it, the musician's act of performing a musical work for an audience of listeners is at the same time an act of providing listeners with something that they enjoy. Thus, the musician's ability to competently bring joy and pleasure to others through their musical performances can provide them with another way in which to feel like they have genuinely accomplished something.

\section{MUSIC AND MEANING}

Finally, musical engagement can afford one a sense of meaning or purpose in life. The emotion that music is capable of soliciting from us may influence our well-being, not only through positively influencing our social interactions and relationships with others, but also by positively influencing our sense of coherence in the world and our sense of identity (Frijda, 1999). Indeed, having a sense of meaning or purpose in life is important, since it has been shown that the absence of meaning in one's life can cause depression (Seligman, 2011). Research has shown that pursuing and making progress toward goals that one finds valuable, such as becoming a more proficient musician, are associated with positive affect, as well as physical and psychological well-being (Diener, 1984; Emmons, 1986; Cantor and Sanderson, 1999). A consistent commitment to goals and tasks may even provide consistency to one's life in times of adversity, helping individuals cope with the various problems they face at each of life's developmental stages (Cantor and Sanderson, 1999). It has been suggested that this is because commitment to particular goals can provide one with a consistent sense of personal agency (Cantor, 1990), structure, and purpose in their daily life (Klinger, 1975; Little, 1983; Cantor and Sanderson, 1999). In this way, musical goals can provide one with a consistent sense of personal agency (e.g., I am a musical performer), structure (e.g., routine practices and performances), and purpose (e.g., I am the alto saxophonist in the band $X$ and play the sax solo in song $Y$ ) in their daily life.

Since an individual that participates with others in a band or musical group is also thereby provided the opportunity to play a distinctive and significant role in something larger than themselves, and as "The Meaningful Life" has often been characterized by positive psychologists as "belonging to and serving something that you believe is bigger than the self" (Seligman, 2011, p. 12), an individual that participates with others in a band or musical group can thereby positively influence their experience of having meaning or purpose in life. For instance, the solo saxophonist during a jazz band performance plays a vital social and esthetic function during the musical context in which all ears are on him, and the ability to come through and deliver in those musical moments keeps his style and identity, as well as his band's, intact. Each band member, as a dependable musical comrade, has a role and a responsibility to the larger band to which they submit themselves as constituent members. And insofar as one consistently performs their social role and responsibility as a contributing musical member, this can provide the musician with a venue through which to continually re-experience a moment of purpose in their life. Various musical performances that the musician has previously accomplished with success could also provide the musician with salient memories of those prized moments when he had served his musical purpose successfully in the past.

\section{POTENTIAL MALADAPTIVE CONSEQUENCES OF MUSICAL ACTIVITY}

It should be mentioned before concluding this article that musical activity does not always or necessarily lead to well-being. In fact, there are various risks associated with musical activity, like any other physically demanding activity that can be done excessively or incorrectly (Sataloff et al., 1991; see also Fishbein et al., 1988; Middlestadt and Fishbein, 1988; Zaza, 1998). Some of these risks are more instrument-specific than others. For instance, pianists are particularly susceptible to musculoskeletal pain and problems in the hands and wrists (Yoshimura et al., 2006), whereas woodwind players are particularly susceptible to problems in the orofacial musculature (Fuks and Fadle, 2002). Others problems, however, are more general and include psychosomatic symptoms associated with performance anxiety (Langendörfer et al., 2006) as well as injuries resulting from inappropriate practicing techniques, poor posture, and poor physical conditioning.

The British Association for Performing Arts Medicine, for instance, conducted a study on 1,046 musicians and found that $52 \%$ of them had problems resulting from technical faults or inappropriate practicing procedures. Specifically, they found that improper performance techniques, excessive practicing without breaks or rest, poor posture, insufficient exercise, and general misuse of the body drastically increased one's susceptibility to music-related injuries (Wynn Parry, 2004, p. 47). Another study by Kreutz et al. (2008) also suggested that "significant proportions of [the] health problems among music performance students emerge from general dispositions, such as posture [which can affect the spine and upper extremities] and fatigue, and thus are not specific to the instrument played" (p. 3). Accordingly, research suggests that musicians wanting to prevent or downplay potential music-related injuries while maximizing music-related benefits should spend an appropriate amount of time warming up, cooling down, and resting at intervals during practice sessions, pay particular attention to the posture of their spine and upper limbs, and maintain a healthy diet and exercising regimen (Wynn Parry, 2004; Kreutz et al., 2008). Kreutz, Ginsborg, and Williamon have suggested that "These [more general] issues should take priority perhaps even over those that are specific to the voice or individual instrument being played" (Kreutz et al., 2008, p. 11). Fortunately, music departments and conservatories have become increasingly aware of the potential risks associated with musical practice and performance, and have been actively creating special programs concerned with both the prevention and treatment of musicrelated injuries (Chesky et al., 2006). For further discussion I refer the reader to the literature (Fishbein et al., 1988; Middlestadt and Fishbein, 1988; Sataloff et al., 1991; Liu and Hayden, 2002; Wynn Parry, 2004; Spahn et al., 2005; Chesky et al., 2006; Williamon and Thompson, 2006; Kreutz et al., 2008, 2009), as a more focused discussion of this topic is admittedly beyond the scope of the present article. 


\section{CONCLUDING REMARKS}

Like any other activity that imposes physical demands on performers, there are potential risks associated with music-related activities; we briefly reviewed some of these and discussed preventive solutions in Section "Potential Maladaptive Consequences of Musical Activity." But as these issues have been discussed elsewhere (Fishbein et al., 1988; Middlestadt and Fishbein, 1988; Sataloff et al., 1991; Liu and Hayden, 2002; Wynn Parry, 2004; Spahn et al., 2005; Chesky et al., 2006; Williamon and Thompson, 2006; Kreutz et al., 2008, 2009), the main purpose of this article was to offer new insight into the question of whether musical activity can positively contribute to one's living a flourishing life. My claim was that musical activity can do this, and throughout the course of this article I have offered new evidence in support of this claim. Specifically, I began by presenting the five commonly recognized factors characteristic of human flourishing or well-being: (1) "positive emotion," (2) "relationships," (3) "engagement," (4) "achievement," and (5) "meaning” (Seligman, 2011, p. 24). In order to determine whether musical activity could actually increase one's level of well-being, we investigated whether it could actually increase one's level of positive emotions, strong interpersonal relationships and rapport with others, commitment in engaging activities, level of accomplishment, and experience of meaning or purpose in life. In Section "Music and Positive Emotion" I argued that music can positively influence one's level of positive emotions, in Section "Music and Relationships" I argued that music can positively influence one's interpersonal relationships and rapport with others, in Section "Music and Engagement"

\section{REFERENCES}

Abbey, A., and Andrews, F. (1985). Modeling the psychological determinants of quality of life. Soc. Indic. Res. 16, $1-34$.

Apter, M. (1982). The Experience of Motivation: The Theory of Psychological Reversals. San Diego: Academic Press.

Argyle, M. (1996). The Social Psychology of Leisure. London: Penguin.

Argyle, M. (1999). "Causes and correlates of happiness," in Well-being: The Foundations of Hedonic Psychol$o g y$, eds D. Kahneman, E. Diener, and N. Schwarz (New York: Russell Sage Foundation Publications), 353-373.

Aristotle. (1911). Nicomachean Ethics, trans. D. Chase. New York: E. P. Dutton \& Co.

Avant, S., Margolin, A., and Salovey, P. (1990-1991). Stress management techniques: anxiety reduction, appeal, and individual differences. Imagin. Cogn. Pers. 10, 3-23.

Bangert, M., and Altenmuller, E. (2003). Mapping perception to action in piano practice: a longitudinal DCEEG study. BMC Neurosci. 4, 26. doi:10.1186/1471-2202-4-26

Bangert, M., Jurgens, U., Hausler, U., and Altenmuller, E. (2006). Classical conditioned responses to absent tones. BMC Neurosci. 7, 60. doi:10.1186/1471-2202-7-60
Bargh, J. (1997). "The automaticity of everyday life," in Advances in Social Cognition, Vol. 10, ed. R. Wyer (Mahwah: Erlbaum), 1-6.

Batson, C., and Ventis, W. (1982). The Religious Experience. New York: Oxford University Press.

Baumeister, R., and Leary, M. (1995). The need to belong: desire for interpersonal attachments as a fundamental human motivation. Psychol. Bull. 117, 497-529.

Bayens, F., Eelen, P., and Van den Bergh, O. (1990). Contingency awareness in evaluative conditioning: a case for unaware affective-evaluative learning. Cogn. Emot. 4, 3-18.

Beauvios, M., and Meddis, R. (1997). Time decay of auditory stream biasing. Percept. Psychophys. 59, 81-86.

Bengtsson, S., Nagy, Z., Skare, S., Forsman, L., Forssberg, H., and Ullen, F. (2005). Extensive piano practicing has regionally specific effects on white matter development. Nat. Neurosci. 8, 1148-1150.

Berscheid, E. (1983). "Emotion," in Close Relationships, ed. H. Kelley (San Francisco: Freeman), 110-168.

Bidelman, G., Gandour, J., and Krishnan, A. (2011). Cross-domain effects of music and language experience on the representation of pitch in human auditory brainstem. J. Cogn. Neurosci. 23, 425-434.

I argued that music can positively influence one's commitment in engaging activities, in Section "Music and Accomplishment" I argued that music can positively influence one's level of accomplishment, and in Section "Music and Meaning" I argued that music can positively influence one's experience of meaning or purpose in life. Thus, throughout the course of this article we have established that musical engagement can positively influence all five of these factors, and as a result, we have compelling evidence that musical engagement can positively contribute to one's living a flourishing life. Since prior to this study there had not yet been a substantive and up-to-date investigation of the possible role of music in contributing to one's living a flourishing life, this study offers a novel contribution to existing work by carrying out this original investigation, thereby bridging the gap and stimulating discussion between the psychology of music and the psychology of well-being.

\section{ACKNOWLEDGMENTS}

I would first and foremost like to thank Marty Seligman and the Positive Psychology Center at the University of Pennsylvania for generously offering me financial support to carry out this research. I have also greatly benefited from conversations with Stephen Amico, Liz Camp, Yale Cohen, Paul Guyer, Robert Kurzban, Jairo Moreno, Carol Muller, Alex Rozin, Paul Rozin, Susan Schneider, and Dmitri Tymoczko, and I owe them much thanks. Finally, I would like to express my gratitude to Dan Lloyd and the two reviewers of this article for their very helpful comments and suggestions.

Blacking, J. (1995). Music, Culture, and Experience. London: University of Chicago Press.

Bloch, C. (2002). Moods and quality of life. J. Happiness Stud. 3, 101-128.

Bloom, B. (1985). Developing Talent in Young People. New York: Ballantine Books.

Brandt, P. (2008). Music and the abstract mind. J. Music Meaning 7, $1-15$.

Brickman, P., and Coates, D. (1987). "Commitment and mental health," in Commitment, Conflict, and Caring, ed. P. Brickman (Englewood Cliffs: Prentice-Hall), 222-309.

Brown, S. (2000a). “The 'musilanguage' model of music evolution," in The Origins of Music, eds N. Wallin, B. Merker, and S. Brown (Cambridge: MIT Press), 271-300.

Brown, S. (2000b). "Evolutionary models of music: from sexual selection to group selection," in Perspectives in Ethology 13: Behavior, Evolution and Culture, eds F. Tonneau and N. Thompson (New York: Plenum Publishers), 231-281.

Buck, J. (1988). Synchronous rhythmic flashing in fireflies II. Q. Rev. Biol. 63, 265-289.

Cantor, N. (1990). From thought to behavior: "Having" and "doing" in the study of personality and cognition. Am. Psychol. 45, 735-750.
Cantor, N., and Sanderson, C. (1999). "Life task participation and wellbeing: the importance of taking part in daily life," in Wellbeing: The Foundations of Hedonic Psychology, eds D. Kahneman, E. Diener, and N. Schwartz (New York: Russell Sage Foundation), 230-243.

Caporael, L., and Brewer, M. (1991). Reviving evolutionary psychology: biology meets society. J. Soc. Issues 47, 187-195.

Carlsen, J. (1981). Some factors which influence melodic expectancy. Psychomusicology 1, 12-29.

Carpentier, J., Mageau, G., and Vallerand, R. (2011). Ruminations and flow: why do people with a more harmonious passion experience higher well-being? J. Happiness Stud. doi: 10.1007/s10902-011-9276-4

Carter, C. (1998). Neuroendocrine perspectives on social attachment and love. Psychoneuroendocrinology 23, 779-818.

Chandrasekaran, B., and Kraus, N. (2010). Music, noise exclusion, and learning. Music Percept. 27, 297-306.

Chandrasekaran, B., Krishnan, A., and Gandour, J. (2009). Relative influence of musical and linguistic experience on early cortical processing of pitch contours. Brain Lang. 108, $1-9$. 
Chase, W., and Simon, H. (1973a). Perception in chess. Cogn. Psychol. 4, $55-81$.

Chase, W., and Simon, H. (1973b). "The mind's eye in chess," in Visual Information Processing, ed. W. Chase (New York: Academic Press), 215-281.

Chesky, K., Dawson, W., and Manchester, R. (2006). Health promotion in schools of music: initial recommendations for schools of music. Med. Probl. Perform. Art. 21, 142-144.

Christensen-Dalsgaard, J. (2004). Music and the origin of speeches. J. Music Meaning 2, 1-16.

Clark, M., Pataki, S., and Carver, V. (1996). "Some thoughts and findings on self-presentation of emotions in relationships," in Knowledge Structures in Close Relationships: A Social Psychological Approach, eds G. Fletcher and J. Fitness (Mahwah: Erlbaum), 247-274.

Clarke, S., and Haworth, J. (1994). "Flow" experience in the daily lives of sixth form college students. Br. J. Psychol. 85, 511-523.

Cohen, S. (1988). Psychosocial models of the role of social support in the etiology of physical disease. Health Psychol. 7, 269-297.

Collins, S., and Kuck, K. (1991). Music therapy in the neonatal intensive care unit. Neonatal Netw. 9, 23-26.

Conard, N., Malina, M., and Munzel, S. (2009). New flutes document the earliest musical tradition in southwestern Germany. Nature 460, 737-740.

Cosmides, L., and Tooby, J. (1994). "Origins of domain specificity: the evolution of functional organization," in Mapping the Mind: Domain Specificity in Cognition and Culture, eds L. Hirschfeld and S. Gelman (New York: Cambridge University Press), 84-116.

Cosmides, L., and Tooby, J. (2000). "Evolutionary psychology and the emotions," in Handbook of emotions, eds M. Lewis and J. HavilandJones (New York: Guilford), 91-115.

Croom, A. (2010a). Thick concepts, non-cognitivism, and Wittgenstein's rule-following considerations. South Afr. J. Philos. 29, 286-309.

Croom, A. (2010b). "Evolutionary theories of musical behavior and cognition" in Poster Presented at the University Of Pennsylvania's Twelfth Annual Summer Workshop in cognitive science and cognitive neuroscience poster session, Philadelphia, PA.

Croom, A. (2011a). Slurs. Lang. Sci. 33, 343-358.
Croom, A. (2011b). Aesthetic concepts, perceptual learning, and linguistic enculturation: considerations from Wittgenstein, language, and music. Integr. Psychol. Behav. Sci. doi: 10.1007/s12124-011-9184-5

Croom, A. (2012). Adaptations, aesthetics, and the evolutionary origins of music. Paper Commissioned for Presentation at the University of Pennsylvania Humanities Forum on Adaptations: 2011-2012, Philadelphia, PA.

Cross, I. (2001). Music, cognition, culture, and evolution. Ann. N. Y. Acad. Sci. 930, 28-42.

Csikszentmihalyi, M. (1975). Beyond Boredom and Anxiety. San Francisco: Jossey Bass.

Csikszentmihalyi, M. (1990). Flow: The Psychology of Optimal Experience. New York: Harper Perennial.

Csikszentmihalyi, M. (1999). If we are so rich, why aren't we happy? Am. Psychol. 54, 821-827.

Darwin, C. (1871). The Descent of Man and Selection in Relation to Sex. London: John Murray.

Delle Fave, A., and Massimini, F. (2004). "Bringing subjectivity into focus: optimal experiences, life themes and person-centered rehabilitation," in Positive Psychology in Practice, eds P. Linley and S. Joseph (Hoboken: Wiley), 581-597.

DeNora, T. (2000). Music in Everyday Life. New York: Cambridge University Press.

Diener, E. (1984). Subjective well-being. Psychol. Bull. 95, 543-575.

Eisenberger, R., Jones, J., Stinglhamber, F., Shanock, L., and Randall, A. (2005). Flow experiences at work: for high need achievers alone? J. Organ. Behav. 26, 755-775.

Elbert, T., Pantev, C., Wienbruch, C., Rockstroh, B., and Taub, E. (1995). Increased cortical representation of the fingers of the left hand in string players. Science 270, 305-307.

Emmons, R. (1986). Personal strivings: an approach to personality and subjective well-being. J. Pers. Soc. Psychol. 47, 1105-1107.

Ericsson, K., Krampe, R., and TeschRomer, C. (1993). The role of deliberate practice in the acquisition of expert performance. Psychol. Rev. 100, 363-406.

Erikson, E. (1950). Childhood and Society. New York: Norton.

Esteves, F., Dimberg, U., and Ohman, A. (1994). Automatically elicited fear: conditioned skin conductance responses to masked facial expressions. Cogn. Emot. 8, 393-414.
Feld, S. (1994). "Lift-up-oversounding," in Music Grooves, eds C. Klein and S. Feld (Chicago: Chicago University Press), 109-156.

Fishbein, M., Middlestadt, S., Ottani, V., Straus, S., and Ellis, A. (1988). Medical problems among ICSOM musicians: overview of a national survey. Med. Probl. Perform. Art. 3, $1-8$.

Fiske, H. (1996). Selected Theories of Music Perception. Lewiston: Edwin Mellen.

Forest, J., Sarrazin, C., Morin, E., Brunet, L., Savoie, A., and Mageau, G. (2008). "La passion harmonieuse et la passion obsessive comme variables pre 'visionnelles de la santé psychologique et de l'état psychologique optimal de flow au travail: Résultats d'une é tude empirique réaliseé aupre's de 118 travailleurs que 'bécois (Harmonious and obsessive passion as predictors of mental health and the optimal psychological state of flow at work: results from an empirical study with 118 Quebec workers)," in Actes du colloque $d u$ $14 e^{\prime}$ me congre's de l'Association Internationale de Psychologie du Travai de Langue Franc aise, eds A. Balikdjian, C. Lemoine, N. Kridis, and P. Salengros (Paris: L'Harmattan), 43-54.

Forgeard, M., Schlaug, G., Norton, A., Rosam, C., Iyengar, U., and Winner, E. (2008). The relation between music and phonological processing in normal-reading children and children with dyslexia. Music Percept. 25, 383-390.

Fox, E. (1996). Selective processing of threatening words in anxiety: the role of awareness. Cogn. Emot. 10, 449-480.

Frank, R. (1988). Passions Within Reason: The Strategic Role of the Emotions. New York: Norton.

Freedman, J. (1978). Happy People. New York: Harcourt Brace Jovanovich.

Freeman, W. (1995). Societies of Brains A Study in the Neuroscience of Love and Hate. Hillsdale: Erlbaum.

Freeman, W. (2000). "A neurobiological role of music in social bonding," in The Origins of Music, eds N. Wallin, B. Merker, and S. Brown (Cambridge: MIT Press), 411-424.

Frijda, N. (1999). "Emotions and hedonic experience," in Well-being: The Foundations of Hedonic Psychology, eds D. Kahneman, E. Diener, and N. Schwarz (New York: Russell Sage Foundation), 190-210.

Fujioka, T., Ross, B., Kakigi, R., Pantev, C., and Trainor, L. (2006). One year of musical training affects development of auditory cortical-evoked fields in young children. Brain 129, 2593-2608.

Fuks, L., and Fadle, H. (2002). "Wind instruments," in The Science and Psychology of Music Performance, eds R. Parncutt and G. McPherson (Oxford: Oxford University Press), 319-334.

Gardner, H. (1993). Creating Minds: An Anatomy of Creativity Seen Through the Lives of Freud, Einstein, Picasso, Stravinsky, Eliot, Graham, and Gandhi. New York: Basic.

Gaser, C., and Schlaug, G. (2003). Brain structures differ between musicians and non-musicians. J. Neurosci. 23 , 9240-9245.

Gilovich, T., and Medvec, V. (1995). The experience of regret: what, when and why. Psychol. Rev. 102, 379-395.

Gollwitzer, P. (1993). "Goal achievement: the role of intentions," in European Review of Social Psychology, Vol. 4, eds W. Stroebe and M. Hewstone (New York: Wiley), 141-185.

Greenfield, M., and Shaw, K. (1983). "Adaptive significance of chorusing with special reference to the Orthoptera," in Orthopteran Mating Systems: Sexual Competition in a Diverse Group of Insects, eds D. Gwynne and G. Morris (Boulder: Westview Press), 1-27.

Habib, M., and Besson, M. (2009). What does music training and musical experience teach us about brain plasticity? Music Percept. 26, 279-285.

Han, S. (1988). "The relationship between life satisfaction and flow in elderly Korean immigrants," in Optimal Experience: Psychological Studies of Flow in Consciousness, eds M. Csikszentmihalyi and I. Csikszentmihalyi (New York: Cambridge University Press), 138-149.

Havighurst, R. (1972). "Life beyond family and work," in Aging in Western Societies, ed. E. Burgess (Chicago: University of Chicago Press), 299-353.

Haworth, J. (1997). Work, Leisure, and Well-Being. London: Routledge.

Haworth, J., and Evans, S. (1995). Challenge, skill, and positive subjective states in the daily life of a sample of YTS students. J. Occup. Organ. Psychol. 68, 109-121.

Haworth, J., and Hill, S. (1992). Work, leisure and psychological well-being in a sample of young adults. J. Community Appl. Soc. Psychol. 2, 147-160.

Hayes, J. (1981). The Complete Problem Solver. Philadelphia: Franklin Institute Press. 
Hayes, J. (1989). “Cognitive processes in creativity," in Handbook of Creativity, eds J. Glover, R. Ronning, and C. Reynolds (New York: Plenum), 135-145.

Heady, B., Holmstrom, E., and Wearing, J. (1985). Models of well-being and ill-being. Soc. Indic. Res. 17, 211-234.

Hicks, F. (1992). The power of music. Nurs. Times 88, 72-74.

Hood, M. (1971). The Ethnomusicologist. New York: McGraw-Hill.

House, J., Landis, K., and Umberson, D. (1988). Social relationships and health. Science 241, 540-545.

Humphrey, N. (1986). The Inner Eye: Social Intelligence in Evolution. New York: Oxford University Press.

Huron, D. (2006). Sweet Anticipation: Music and the Psychology of Expectation. Cambridge: MIT Press.

Hutchinson, S., Lee, L., Gaab, N., and Schlaug, G. (2003). Cerebellar volume of musicians. Cereb. Cortex 13, 943-949.

Irwin, W. (2011). Art and the category of being aesthetic: a neoWittgensteinian account. J. Value Inq. 45, 59-66.

James, W. (1884). What is emotion? Mind 19, 188-205.

James, W. (1890). The Principles of Psychology, Volumes 1-2. New York: Holt.

James, W. (1894). The physical basis of emotion. Psychol. Rev. 7, 516-529.

Juslin, P., and Sloboda, J. (2001). Music and Emotion: Theory and Research. Oxford: Oxford University Press.

Kaminski, J., and Hall, W. (1996). The effect of soothing music on neonatal behavioral states in the hospital newborn nursery. Neonatal Netw. 16, 45-54.

Kaufman, D. (2007). Family resemblances, relationalism, and the meaning of 'art'. Br. J. Aesthet. 47, 280-297.

Kessler, R., and Essex, M. (1982). Marital status and depression: the importance of coping resources. Soc. Forces 61, 484-505.

Klinger, F. (1975). Consequences of commitment to a disengagement from incentives. Psychol. Rev. 82, $1-25$.

Klump, G., and Gerhardt, H. (1992). "Mechanisms and function of calltiming in male-male interactions in frogs," in Playback and Studies of Animal Communication, ed. P. McGregor (New York: Plenum Press), 153-174.

Koelsch, S. (2010). Towards a neural basis of music-evoked emotions. Trends Cogn. Sci. (Regul. Ed.) 11, 131-137.
Kosfeld, M., Heinrichs, M., Zak, P., Fischbacher, U., and Fehr, E. (2005). Oxytocin increases trust in humans. Nature 435, 673-676.

Kreutz, G., Ginsborg, J., and Williamon, A. (2008). Music students' health problems and health promoting behaviours. Med. Probl. Perform. Art. 23, 3-11.

Kreutz, G., Ginsborg, J., and Williamon, A. (2009). Health-promoting behaviours in conservatoire students. Psychol. Music 37, 47-60.

Krueger, J. (2011). Doing things with music. Phenom. Cogn. Sci. 10, 1-22.

Kubovy, M. (1999). "On the pleasures of the mind," in Well-being: The Foundations of Hedonic Psychology, eds D. Kahneman, E. Diener, and N. Schwarz (New York: Russell Sage Foundation), 134-154.

Kujala, T., Karma, K., Ceponiene, R., Belitz, S., Turkkila, P., Tervaniemi, M., and Naatanen, R. (2001). Plastic neural changes and reading improvement caused by audiovisual training in reading-impaired children. Proc. Natl. Acad. Sci. U.S.A. 98, 10509-10514.

Landman, J. (1993). Regret: The Persistence of the Possible. New York: Oxford University Press.

Lang, P. (1995). The emotion probe. Am. Psychol. 50, 372-385.

Lange, C. (1922). The Emotions, First Published in 1885, trans. I. Haupt. Baltimore: Williams \& Wilkins.

Langendörfer, F., Hodapp, V., Kreutz, G., and Bongard, S. (2006). Personality and performance anxiety among professional orchestra musicians. J. Individ. Dif. 27, 162-171.

Laukka, P. (2007). Uses of music and psychological wellbeing among the elderly. J. Happiness Stud. 8, 215-241.

Lazarus, R. (1991). Emotion and Adaptation. New York: Oxford University Press.

Lehrer, P., and Wookfolk, R. (1993). Principles and Practice of Stress Management, 2nd Edn. New York: Guilford.

Leventhal, L., and Scherer, K. (1987). The relationship of emotion to cognition: a functional approach to a semantic controversy. Cogn. Emot. 1, 3-28.

Levitin, D. (2006). This is Your Brain on Music: The Science of a Human Obsession. New York: Dutton.

Little, B. (1983). Personal projects: a rationale and methods for investigation. Environ. Behav. 15, 273-309.

Liu, S., and Hayden, G. (2002). Maladies in musicians. South. Med. J. 95, 727-734.
Lomax, A. (1968). Folk Song Style and Culture. New Brunswick: Transaction Books.

Lutz, C. (1988). Unnatural Emotions: Everyday Sentiments on a Micronesian Atoll and Their Challenge to Western Theory. Chicago: University of Chicago Press.

Mageau, G., Vallerand, R., Rousseau, F., Ratelle, C., and Provencher, P. (2005). Passion and gambling: investigating the divergent affective and cognitive consequences of gambling. J. Appl. Soc. Psychol. 35, 100-118.

Magnan, A., Ecalle, J., Veuillet, E. and Collet, L. (2004). The effects of audio-visual training program in dyslexic children. Dyslexia 10 131-140.

Mandler, G. (1975). Mind and Emotion. New York: Wiley.

Markus, H., and Kitayama, S. (1991) Culture and the self: implications for cognition, emotion, and motivation. Psychol. Rev. 98, 224-253.

McCraty, R., Atkinson, M., Rein, G., and Watkins, A. (1996). Music enhances the effect of positive emotional states on salivary IgA. Stress Med. 12 167-175.

McNeill, W. (1995). Keeping Together in Time: Dance and Drill in Human History. Cambridge: Harvard University Press.

Merker, B. (2000). "Synchronous chorusing and human origins," in The Origins of Music, eds N. Wallin, B. Merker, and S. Brown (Cambridge: MIT Press), 315-327.

Merriam, A. (1964). The Anthropology of Music. Evanston: Northwestern University Press.

Mesquita, B., Frijda, N., and Scherer, K. (1997). "Culture and emotion," in Handbook of Cross-Cultural Psychology, Vol. 2, eds P. Dasen and T. Saraswathi (Boston: Allyn and Bacon), 255-298.

Meyer, L. (1956). Emotion and Meaning in Music. Chicago: University of Chicago Press.

Meyer, L. (1973). Explaining Music. Berkeley: University of California Press.

Meyer, W., Niepel, M., Rudolph, U., and Schutzwohl, A. (1991). An experimental analysis of surprise. Cogn. Emot. 5, 295-311.

Middlestadt, S., and Fishbein, M. (1988). Health and occupational correlates of perceived occupational stress in symphony orchestra musicians. J. Occup. Med. 30, 687-692.

Miller, G. (2000). "Evolution of human music through sexual selection," in The Origins of Music, eds N. Wallin, B. Merker, and S.
Brown (Cambridge: MIT Press), 329-360.

Miller, G. (2009). Proposal to slash salaries riles California researchers. Science 325, 19.

Mischel, W., Cantor, N., and Feldman, S. (1996). "Principles of selfregulation: the nature of willpower and self-control," in Social Psychology: Handbook of Basic Principles, eds E. Higgins and A. Kruglanski (New York: Guilford), 329-360.

Molnar-Szakacs, I., and Overy, K. (2006). Music and mirror neurons: from motion to 'e'motion. Soc. Cogn. Affect. Neurosci. 1, 235-241.

Murphy, S., and Zajonc, R. (1993). Affect, cognition, and awareness: affective priming with optimal and suboptimal stimulus exposures. J. Pers. Soc. Psychol. 64, 723-739.

Myers, D. (1999). "Close relationships and quality of life," in Well-Being: The Foundations of Hedonic Psychology, eds D. Kahneman, E. Diener, and N. Schwarz (New York: Russell Sage Foundation Publications), 374-391.

Nakamura, J., and Csikszentmihalyi, M. (2002). "The concept of flow," in Handbook of Positive Psychology, eds C. Snyder and S. Lopez (Oxford: Oxford University Press), 89-105.

Narmour, E. (1991). The top-down and bottom-up systems of musical implication: building on Meyer's theory of emotional syntax. Music Percept. 9, 1-26.

Needham, N., Wang, L., and Robinson, K. (1962). "Physics," in Science and Civilization in China, Vol. 4.1, ed. N. Needham (Cambridge: Cambridge University Press), 126-228.

Nelson, N. (1988). A Meta-Analysis of the Life-Event/Health Paradigm: The Influence of Social Support. Ph.D. dissertation, Temple University, Philadelphia.

Nicol, J. (2010). Body, time, space and relationship in the music listening experiences of women with chronic illness. Psychol. Music 38, 351-367.

Nilsson, U. (2009). The effect of music intervention in stress response to cardiac surgery in a randomized clinical trail. Heart Lung 38, 201-207.

Olson, J., Roese, M., and Zanna, M. (1996). "Expectancies," in Social Psychology: Handbook of Basic Principles, eds E. Higgins and W. Kruglanski (New York: Guilford Press), 211-238.

Otte, D. (1977). "Communication in Orthoptera," in How Animals Communicate, ed. T. Sebeok (Bloomington: Indiana University Press), 334-361. 
Parbery-Clark, A., Skoe, E., Lam, C., and Kraus, N. (2009). Musician enhancement for speech-in-noise. Ear Hear. 30, 653-661.

Pascual-Leone, A., Nguyen, D., Cohen, L., Brasil-Neto, J., Cammarota, A., and Hallett, M. (1995). Modulation of muscle responses evoked by transcranial magnetic stimulation during the acquisition of new fine motor skills. J. Neurophysiol. 74, 1037-1045.

Pates, J., Karageorghis, C., Fryer, R., and Maynard, I. (2003). Effects of asynchronous music on flow states and shooting performance among netball players. Psychol. Sport. Exerc. 4, 415-427.

Peretz, I., Blood, A., Penhune, V., and Zatorre, R. (2001). Cortical deafness to dissonance. Brain 124, 928-940.

Peretz, I., and Zatorre, R. (2005). Brain organization for music processing. Annu. Rev. Psychol. 56, 89-114.

Perlman, D., and Rook, K. (1987). "Social support, social deficits, and the family: toward the enhancement of well-being," in Family Processes and Problems: Social Psychological Aspects, ed. S. Oskamp (Newbury Park: Sage), 17-44.

Pettijohn, T., and Pettijohn, T. (1996). Perceived happiness of college students measured by Maslow's hierarchy of needs. Psychol. Rep. 79, 759-762.

Philippe, F., Vallerand, R., Andrianarisoa, J., and Brunel, P. (2009). Passion in referees: examining their affective and cognitive experiences in sport situations. J. Sport Exerc. Psychol. 31, 77-96.

Putnam, R. (1995). Bowling alone: America's declining social capital. $J$. Democracy 6, 65-78.

Richman, B. (1987). Rhythm and melody in Gelada vocal exchanges. Primates 28, 199-223.

Richman, B. (2000). "How music fixed 'nonsense' into significant formulas: on rhythm, repetition, and meaning," in The Origins of Music, eds N. Wallin, B. Merker, and S. Brown (Cambridge: MIT Press), 301-314.

Rosch, E., and Mervis, C. (1975). Family resemblances: studies in the internal structure of categories. Cogn. Psychol. 7, 573-605.

Rosenkranz, K., Williamon, A., and Rothwell, J. (2007). Motorcortical excitability and synaptic plasticity is enhanced in professional musicians. J. Neurosci. 27, 5200-5206.

Rozin, P. (1999). "Preadaptation and the puzzles and properties of pleasure," in Well-Being: The Foundations of Hedonic Psychology, eds D. Kahneman, E. Diener, and N. Schwarz
(New York: Russell Sage Foundation), 109-133.

Salimpoor, V., Benovoy, M., Larcher, K., Dagher, A., and Zatorre, R. (2011). Anatomically distinct dopamine release during anticipation and experience of peak emotion to music. Nat. Neurosci. 14, 257-262.

Santos, A., Joly-Pottuz, B., Moreno, S., Habib, M., and Besson, M. (2007). Behavioral and event-related potentials evidence for pitch discrimination deficits in dyslexic children: improvement after intensive phonic intervention. Neuropsychologia 45, 1080-1090.

Sarkamo, T., Tervaniemi, M., Laitinen, S., Forsblom, A., Soinila, S., Mikkonen, M., Autti, T., Silvennoinen, H., Erkkila, J., Laine, M., Peretz, I., and Hietanen, M. (2008). Music listening enhances cognitive recovery and mood after middle cerebral artery stroke. Brain 131, 866-876.

Sataloff, R., Brandfonbrener, A., and Lederman, R. (eds). (1991). Textbook of Performing Arts Medicine. New York: Raven Press.

Schellenberg, E. (1996). Expectancy in melody: tests of the implicationrealization model. Cognition 58, 75-125.

Schlaug, G., Jancke, L., Huang, Y., Staiger, J., and Steinmetz, H. (1995). Increased corpus callosum size in musicians. Neuropsychologia 33, 1047-1055.

Schneider, P., Scherg, M., Dosch, H., Specht, H., Gutschalk, A., and Rupp, A. (2002). Morphology of Heschl's gyrus reflects enhanced activation in the auditory cortex of musicians. Nat. Neurosci. 5, 688-694.

Seeger, A. (1987). Why Suya Sing. Cambridge: Cambridge University Press. Seligman, M. (2011). Flourish: A Visionary New Understanding of Happiness and Wellbeing. New York: Free Press.

Shahin, A., Roberts, L., Chau, W., Trainor, L., and Miller, L. (2008). Music training leads to the development of timbre-specific gamma band activity. Neuroimage 41, $113-122$.

Spahn, C., Burger, T., Hildebrandt, H., and Seidenglanz, K. (2005). Health locus and preventive behaviour among students of music. Psychol. Music 33, 256-268.

Standley, J. (2001). Music therapy for the neonate. Newborn Infant Nurs. Rev. 1, 211-216. Strait, D., Kraus, N., Parbery-Clark, prising Guideposts to a Happier Life A., and Ashley, R. (2010). Musical From the Landmark Harvard Study of experience shapes top-down audi- Adult Development. New York: Little, tory mechanisms: evidence from masking and auditory attention performance. Hear. Res. 261, 22-29.

Strait, D., Kraus, N., Skoe, E., and Ashley, R. (2009). Musical experience and neural efficiency: effects of training on subcortical processing of vocal expressions of emotion. Eur. J. Neurosci. 29, 661-668.

Sudnow, D. (1978). Ways of the Hand: The Organization of Improvised Conduct. New York: Knopf.

Sudnow, D. (1979). Talk's Body: A Meditation Between Two Keyboards. New York: Knopf.

Suls, J. (1972). “Two-stage model for the appreciation of jokes and cartoons: information-processing analysis," in The Psychology of Humor, eds $\mathrm{J}$. Goldstein and P. McGhee (San Diego: Academic Press), 81-100.

Suls, J. (1977). "Cognitive and disparagement theories of humor: a theoretical and empirical synthesis," in It's a Funny Thing, Humor, eds A. Chapman and H. Foot (Elmsford: Pergamon Press), 41-45.

Tilghman, B. (2008). Kaufman on art, family resemblances, and Wittgenstein. Br. J. Aesthet. 48, 86-88.

Trainor, L., McDonald, K., and Alain, C. (2002). Automatic and controlled processing of melodic contour and interval information measured by electrical brain activity. J. Cogn. Neurosci. $14,430-432$.

Trainor, L., Shahin, A., and Roberts, L. (2003). Effects of musical training on the auditory cortex in children. Ann. N. Y. Acad. Sci. 999, 506-513.

Trainor, L., Shahin, A., and Roberts, L. (2009). Understanding the benefits of musical training: effects on oscillatory brain activity. Ann. N. Y. Acad. Sci. 1169, 133-142.

Trappe, H. (2010). The effects of music on the cardiovascular system and cardiovascular health. Heart 96, 1868-1871.

Trevarthen, C. (1999). "Musicality and the intrinsic motive pulse: evidence from human psychobiology and infant communication," in Rhythms, Musical Narrative, and the Origins of Human Communication, ed. I. Deliège (Liege: European Society for the Cognitive Sciences of Music), 157-213.

Turnbull, C. (1966). Wayward Servants. Garden City: Natural History.

Unyk, A., and Carlsen, J. (1987). The influence of expectancy on melodic perception. Psychomusicology $7,3-23$

Vaillant, G. (2003). Aging Well: SurFrom the Landmark Harvard Study of Brown and Company.
Vallerand, R., Blanchard, C., Mageau, G., Koestner, R., Ratelle, C., Léonard, M., Gagné, M., and Marsolais, J. (2003). Les passions de l âme: on obsessive and harmonious passion. J. Pers. Soc. Psychol. 85, 756-767.

Vernon, P. (1970). Creativity: Selected readings. Baltimore: Penguin Books.

Watanabe, D., Savion-Lemieux, T., and Penhune, V. (2007). The effect of early musical training on adult motor performance: evidence for a sensitive period in motor learning. Exp. Brain Res. 176, 332-340.

Weisberg, R. (1999). "Creativity and knowledge: a challenge to theories," in Handbook of Creativity, ed. R. Sternberg (New York: Cambridge University Press), 226-250.

Weisberg, R. (2006). Creativity: Understanding Innovation in Problem Solving, Science, Invention, and the Arts. Hoboken: John Wiley \& Sons.

Weitz, M. (1956). The role of theory in aesthetics. J. Aesthet. Art Criticism 15, 27-35.

Wells, K. (1977). The social behavior of anuran amphibians. Anim. Behav. 25, 666-693.

Williamon, A., and Thompson, S. (2006). Awareness and incidence of health problems among conservatoire students. Psychol. Music 34, 411-430.

Wittgenstein, L. (1953). Philosophical Investigations. Oxford: Blackwell.

Wong, P., Skoe, E., Russo, N., Dees, T., and Kraus, N. (2007). Musical experience shapes human brainstem encoding of linguistic pitch patterns. Nat. Neurosci. 10, 420-422.

Wrangham, R. (1975). The Behavioral Ecology of Chimpanzees in Gombe National Park, Tanzania. Doctoral dissertation, University of Cambridge, Cambridge.

Wrangham, R. (1979). On the evolution of ape social systems. Soc. Sci. Int. 18, 335-368.

Wyer, R., and Collins, J. (1992). A theory of humor elicitation. Psychol. Rev. 99, 663-688.

Wynn Parry, C. (2004). "Managing the physical demands of musical performance," in Musical Excellence: Strategies and Techniques to Enhance Performance, ed. A. Williamon (New York: Oxford University Press), 41-60.

Yoshimura, E., Paul, P., Aerts, C., and Chesky, K. (2006). Risk factors for piano-related pain among college students. Med. Probl. Perform. Art. 21, 118-125.

Zajonc, R. (1980). Thinking and feeling: preferences need no inferences. Am. Psychol. 35, 151-175. 
Zatorre, R., Chen, J., and Penhune, V. (2007). When the brain plays music: auditory-motor interactions in music perception and production. Nat. Rev. Neurosci. 8, 547-558.

Zaza, C. (1998). Playing-related musculo-skeletal disorders in musicians: a systematic review of incidence and prevalence. Can. Med. Assoc. J. 158, 1019-1025.
Zillmann, D., Weaver, J., Mundorf, N., and Aust, C. (1986). Effects on an opposite-gender companion's affect to horror on distress, delight, and attraction. J. Pers. Soc. Behav. 51, 586-594.

Conflict of Interest Statement: The author declares that the research was conducted in the absence of any commercial or financial relationships that could be construed as a potential conflict of interest.

Received: 22 September 2011; accepted: 15 December 2011; published online: 02 January 2012.

Citation: Croom AM (2012) Music, neuroscience, and the psychology of wellbeing: a précis. Front. Psychology 2:393. doi: 10.3389/fpsyg.2011.00393
This article was submitted to Frontiers in Theoretical and Philosophical Psychology, a specialty of Frontiers in Psychology. Copyright (c) 2012 Croom. This is an open-access article distributed under the terms of the Creative Commons Attribution Non Commercial License, which permits non-commercial use, distribution, and reproduction in other forums, provided the original authors and source are credited. 